\title{
A Review of Occupational Health Implications of Exposure and Risk Management of Carbon Nanotubes and Carbon Nanofibers
}

\author{
Emmanuel A. Iyiegbuniwe, Usonwanne U. Nwosu, and Sireesha Kodali
}

\begin{abstract}
In the last decade, available research studies on industrial and biomedical applications have documented the potential for significant health effects from exposure to carbon nanotubes (CNTs) and carbon nanofibers (CNFs). This paper reviews existing information on toxicity and potential health risks from occupational exposures to CNTs and CNFs. Additionally, the paper discusses the need to consider the Precautionary Principle as a basis for risk management practices for effectively controlling exposures to CNTs and CNFs. It must be noted that in order to effectively evaluate workers' exposures and minimize risks for respiratory hazards, a multi-tiered measurement strategy and feasible interventions or controls must be developed with a view to controlling exposures below NIOSH's recommended exposure limit of 1.0 $\mu \mathrm{g} / \mathrm{m3over}$ a working lifetime of 45 years. The application of classical industrial hygiene exposure controls (engineering, administrative control/work practices, and personal protective equipment) are recommended.
\end{abstract}

Index Terms - Carbon nanotubes, carbon nanofibers, toxicity, occupational exposure limits, engineering control, work-practice control, personal protective equipment.

\section{INTRODUCTION}

Carbon nanotubes (CNTs) and carbon nanofibers (CNFs) constitute a class of newly developed elongated man-made nanoparticles comprised of microscopic sheets of pure carbon [1]. CNTs and CNFs are tiny, cylindrical, large aspect ratio manufactured allotropes of carbon with relevant components of nanotechnology. Because of their many novel and useful properties for hundreds of products used in cosmetics, clothing, and biomedical research, there has been a steady increase in global production and application of these nanomaterials during the last decade [1], [2]. As a result of their unique characteristics, they have become widely desirable for incorporation as additives into consumer and commercial materials [3]. These unique characteristics of CNFs and CNTs include thermal conductivity, mechanical and electrical properties as well as frequency shielding properties [3]. It has been speculated by various scientists that by 2020 , the nanotechnology industry would account for about 2 million workers with a projected market value of $\$ 19.6$ billion by 2015 [3]. Due to increasing use of these materials in recent times, there have been growing concerns about their hazardous effects on health especially following

Manuscript received August 8, 2015, revised January 28, 2016.

The authors are with the Department of Public Health, Western Kentucky University, Bowling Green, KY 42101, USA (e-mail: emmanuel.iyiegbuniwe@wku.edu). occupational exposure via inhalation and dermal absorption.

CNTs are often visualized as a single sheet of graphite rolled to form a seamless cylinder. According to NIOSH [1], there is currently no single type of CNTs and they can be differentiated based on shape, size, physical attributes, surface coatings, chemistry, or surface characteristics. CNTs are classified into two distinct types: single-walled carbon nanotubes (SWCNT) and multiwalled carbon nanotubes (MWCNT). SWCNT have been reported to be physically strong and stiff and are known to be 10 times as strong as steel and 1.2 times as stiff as diamond [4]. MWCNT are larger and composed of many single-walled tubes stacked one inside the other [1]. In 2006, the estimated global revenues from CNT production was approximately $\$ 230$ million, a whopping growth rate of $\sim 170 \%$ [4]. It was also estimated that between 2008 and 2010, the production of CNTs rose from 390 to 3400 tons -a significant increase in demand for these materials [5].

The biological mode of action for CNTs and CNFs are attributed to their physical and chemical properties including nanostructure, fiber shape, and their graphitic structure [4]. In addition, CNT and CNF have heterogeneous structures that differ in size, metal contaminants, surface chemistry, and the tendency to aggregate or agglomerate. Unlike CNTs, carbon nanofibers are strands of layered graphite sheets that range in size from 50 to $200 \mathrm{~nm}$ [6]. The multiwall CNTs exist as tubes just like the names suggest and have the ability to form bundled or entangled structures. On the contrary the single wall CNTs due to their smaller size have the ability to form highly entangled structures when compare to the other two [6]. The alignment of the grapheme plane is the main differentiating factor between the carbon nanotubes and nanofibers; with the plane and fiber axis parallel within the carbon nanotubes and not parallel within the carbon nanofibers [7]. In addition, they have been thought to increase the durability and resistance of products with which they are manufactured when compared to other materials like aluminum or steel. They have been widely used as coatings and composites in the production of automobile and aerospace parts, as well as sporting materials [7]. Other uses of CNTs and CNFs include the production of batteries, fuel cells, flat panel displays and memory devices [5].

It is important to distinguish between incidental nanoparticles (by-products of activities such as welding, soldering and combustion) from engineered nanomaterial that are discussed in this article. This is especially important in the process of assessing the risks associated with inhalation of these engineered particles in the work place because the 
toxicity of the engineered particle will differ from one another and from incidental particles [7]. It is imperative that all hazards associated with CNTs and CNFs must be widely studied to develop adequate and effective control strategies to prevent adverse health effects of these materials.

This paper aims to review recent literature regarding toxicity and occupational exposure to CNTs and CNFs and to discuss strategies for controlling such exposures. Although, most of the available literature has discussed nanoparticles in general, this paper also examines the toxicological properties of CNT and CNF and a conceptual framework for occupational health and safety recommended guidelines as well as current approaches for risk management and workplace exposure controls.

\section{THEORETICAL FRAMEWORK}

The precautionary principle, first recognized by the United Nations' General Assembly and incorporated into the World Charter for Nature in 1982, states that "When an activity raises threats of harm to the environment or human health, precautionary measures should be taken even if some cause-and-effect relationships are not fully established scientifically" [8]. The principle has been applied in international environmental law, particularly in the management of hazardous wastes, pollution prevention, global climate change, and protection of endangered species. Examples of international treaties where the principle has been applied included the United Nations' Rio Declaration (Principle 15), Cartagena Protocol on Biosafety, and the Stockholm Convention on Persistent Organic Pollutants [8].

The precautionary principle has long been proposed as a new guideline in environmental decision making process, can be viewed as comprising of four central components: "taking preventive action in the face of uncertainty; shifting the burden of proof to the proponents of an activity; exploring a wide range of alternatives to possibly harmful actions; and increasing public participation in decision making." [9]. also stated that "Where there are threats of serious or irreversible damage, lack of full scientific certainty shall not be used as a reason for postponing cost-effective measures to prevent environmental degradation [9].

In general, the precautionary principle requires that public health protection be considered first before any commercial interests for all products introduced into commerce. Manufacturers of new products that intended to be introduced into commerce have considered it the juridical equivalent of "guilty until proven innocent." Although the precautionary principle operates in the context of scientific uncertainty, it is important to emphasize that proponents consider it to be applicable only when there is good reason to believe that harmful effects might occur, based on the best available scientific advice [9].

\section{TOXICITY, EXPOSURE AND RISK ASSESSMENT}

\section{A. Toxicity}

Nanoparticles are generally considered materials of significant public health importance due to their ability to enter the human body through various routes of exposure including inhalation, absorption, and/or ingestion [10]. A number of toxicological studies have demonstrated that relatively low doses of CNTs and CNFs are associated with adverse lung effects (e.g., pulmonary inflammation, persistent fibrosis, etc.) in rodents [1], [10]. However, such adverse health effects have not been shown to occur in humans but researchers have noted the need to control worker exposure.

In a recent study, NIOSH researchers injected a group of laboratory mice with a known cancer initiator called methylcholanthrene and exposed them to airborne concentration of MWCNT while the control group was injected with saline solution [1]. The purpose of the NIOSH study was to investigate whether MWNCT by itself would initiate cancer in mice, or would promote cancer in conjunction with methylcholanthrene. The authors concluded that the experimental mice were significantly more likely to develop cancers when compared to the control group. Also, the experimental mice developed larger size tumors. The study noted that the toxicological results further showed that exposure to MWCNT was sufficient to increase the risk of cancer in mice exposed to a known carcinogen, but fell short of suggesting that MWCNTs alone caused cancer in mice [1].

As described in the current intelligence bulletin by $\mathrm{NIOSH}$ [1], the toxicological profile for CNTs and CNFs has advanced to make specific medical surveillance and screening recommendations for exposed workers. Hence, the strong evidence for pulmonary fibrosis from animal studies coupled with the fact that such effects can be detected by medical tests, was the basis for NIOSH's recommendation for specific medical screenings for potentially exposed workers.

\section{B. Effects of Exposure and Risk Assessment}

The assessment of any risks associated with the exposure to airborne nanoparticles require a non-conventional method considering the fact that their mass is insignificant when compared to the heavier particles that contribute most to mass concentration [5], [11]. Occupational exposures to CNTs and CNFs have been reported to occur during manufacturing processes and the incorporation and application of these materials into other products [1]. Most of the concern about exposure is in the work place, with intradermal and inhalation routes being the known possible means of exposure.

Interestingly, the adverse effects of CNTs and CNFs are dependent on their physicochemical properties; and associated to a great extent with the number of particles and the surface area concentration of the nanoparticle when compared with the particle mass concentration [7]. Some of these characteristics that determine the toxicity of these particles include size, surface coating, the shape, solubility, charge, and the functional group attached to the particle [1]. In addition with a greater surface area for a given mass of particle, the inflammogenic toxicity and tumorigenic responses is increased [7].

There have been some conceptions about the various means by which a worker can be exposed to CNTs and CNFs in the work environment and the acceptable method for exposure assessment [12]. There has been no consensus on the defined exposure metric (for instance mass, particle 
number, concentration, surface area); which can be used to measure such exposures and the resultant toxic effects [13]. The presence of incidental nanoparticles generated during combustion activities would make it difficult to quantitatively interpret worker exposure [13]. This difficulty can also be attributed to the difference that exists between these particles and other larger particles with similar chemical constituents. The risk of respiratory exposure is higher in an enclosed place and can be increased if these particles are generated in the gaseous phase thereby causing the release of aerosols in to the environment; increased agitation can result in the production of airborne particles that can be inhaled; the dust collection systems used in the production of nanoparticles serve as a source of respiratory exposure; processes such as drilling, sanding or mechanical disruption lead to the production of aerosols and hence the risk of inhalation of particles [13]. Dermal exposure on the other hand commonly occurs when the nanomaterials are in liquid form especially in the absence of adequate protective measures. In addition, processes like pouring, mixing, spillage cleanup also pose a risk of dermal exposure [1], [13].

A review of current literature showed that only a limited number of studies have documented deleterious human health effects from exposure to CNTs and CNFs while the results of other studies have been inconclusive. A study conducted by Evans et al. [14] used a novel dustiness testing device to disperse and aerosolize particles of test materials containing carbon nanomaterials including nanofibers and nanotubes. Dustiness was defined as the ability of a substance to form airborne particles following the application of any form of mechanical stimulus. They noted that a material with high dustiness had greater potential of being inhaled by workers and thus demonstrated a high level of dustiness with carbon nanofibers and nanotubes. In addition, the respirable dustiness comprised about one third of the total dustiness indicating a linear relationship between the variables tested [14]. The results of the study showed that some of the inhaled particles may be able to reach the lungs and cause respiratory health problems. In a study by Maynard et al. [15] to determine exposure to SWCNT during the handling of unrefined material, the concentrations obtained were low despite the presumption of laboratory studies about the release of fine particles from CNTs in the presence of agitation. Both dermal and airborne exposures were considered during the study. Concentrations of airborne CNTs was less than $53 \mu \mathrm{g} / \mathrm{m}^{3}$ while those deposited on the gloves ranged between 0.2 and $6 \mathrm{mg} / \mathrm{hand}$ [15].

Inhalation studies of animals have shown that some CNTs and CNFs have the potential to deposit in the alveolar region of the lungs and cause inflammation, DNA damage, oxidative stress, granuloma formation and fibrosis by the macrophages [16]. In addition, the ability to deposit in the blood stream and the olfactory lobe of the brain following inhalation has also been noted [16]. Hence, there is the need to exercise caution and prevent human exposure. Similarly, some animal studies have revealed the possibility of dermal inflammation following exposure to CNTs with resultant effects on the cardiovascular and immune systems while the possibility of crossing the blood brain barrier is still all still being investigated [15].
Risk assessment uses standardized tools and procedures to characterize the uncertainties associated with potential health risks of exposure to hazardous substances [11]. It seeks to provide important and fundamental information based on using the best available data and scientific methods that lead to the development of risk management options as the basis for public and occupational health decision-making [1]. In the United States, the standard risk assessment paradigm is based on the following four distinct steps: Hazard Assessment, Exposure Assessment, Dose-response Analysis, and Risk Characterization. The methods that rely on mass concentration would be inappropriate for characterizing risks from exposure to CNTs and CNFs. It is therefore important to perform a risk assessment to determine the quantitative and qualitative risk associated with CNTs and CNFs. This involves recognizing occupational activities that are associated with the highest risk of exposure among the workers. [4]. Also, it is important that the exposure scenarios that may be associated with both the production and use of the engineered nanoparticles are considered during the risk assessment process.

In a recent report, NIOSH [1] noted that the nonmalignant pulmonary data from animal studies of CNT are the best data in determining quantitative risk assessment and this forms the basis for a recommended exposure limit (REL). Recognition of these hazards would require that employers implement adequate measures to control exposures to CNTs and CNFs. However some constraints have been associated with proper execution of a risk assessment associated with carbon nanofibers and nanotubes. These include a lack of consensus on the aerosol standards and metrics to be utilized; insufficient data regarding translocation and toxicity and effective testing strategies; reliable exposure scenarios are lacking; the technology required for monitoring these exposure are not cost-effective and are scarce; unavailability of exposure data and models.

In a previous study, NIOSH [1], [17] reviewed three major sources of uncertainty in CNT risk assessment, including: Critical effect or lung response measure (i.e., level of severity); dose rate and retention assumptions for extrapolation from sub-chronic or short-term animal studies to chronic exposure in humans; and low dose extrapolation using the benchmark dose models to estimate risks below the $10 \%$ benchmark dose. The other areas of uncertainty, but with less significance included dose estimation using benchmark, route of exposure and its impact, and dose estimation using the lung of a rat [1]. In addition, depending on the exposure scenario applied, uncertainties often result in over-estimation of the true health risk to workers or the reverse - under-estimation.

\section{Occupational Exposure Limits}

There is a paucity of research studies on potential adverse health effects and acceptable occupational exposure limits of engineered nanomaterials. There are no existing regulatory or recommended limits for occupational exposure to carbon nanotubes and nanofibers laid down by regulatory bodies. However, some guidelines have been established by various agencies or organizations worldwide. A number of countries have established personal exposure limits (for airborne aerosols or fibers in workplace atmospheres e.g., permissible 
exposure limit as set forth by the Occupational Safety and Health Administration in the United States). The currently proposed occupational exposure limits for CNTs should be in the range of 1 to $50 \mu \mathrm{g} / \mathrm{m}^{3}$, as an 8-hourr TWA concentration [1]. NIOSH has established a recommended exposure limit (REL) of $1 \mu \mathrm{g} / \mathrm{m}^{3}$ as an 8-hour time weighted average (TWA) to all CNTs and CNFs exposures for respirable elemental carbon. According to NIOSH, the aim of the REL is to minimize adverse effects on the lungs that may occur with exposure at this concentration over a long period of time [1]. A concentration of $1 \mu \mathrm{g} / \mathrm{m}^{3}$ is considered the least airborne concentration that can be assessed with a reasonable degree of accuracy [1]. NIOSH also noted that until research results can fully explain the physical-chemical properties of CNTs and CNFs that define their inhalation toxicity, all types of CNTs and CNFs should be considered respiratory hazards, hence exposures must be controlled below the REL.

\section{EXPOSURE EVALUATION}

\section{A. Exposure Monitoring}

Exposure monitoring and assessment of the worker and the workplace are essential steps in determining compliance with applicable regulations or guidelines and developing necessary control measures. The main purpose of occupational exposure monitoring include: Compliance with applicable occupational health and safety regulations, Employee health risk assessment, Determination of the need for engineering controls, Documentation for Worker's Compensation claims, Documentation for litigation purposes, Provision of information to occupational health physicians, Incident/complaint investigation, Complement biological monitoring results, and Selection of personal protective equipment (PPE).

According to NIOSH [17], until additional data becomes available, measurement of mass-based airborne concentrations of respirable particles is recommended for monitoring worker exposure to CNTs and CNFs [1]. The recommended method for determining personal exposure concentrations to CNT and CNF is by elemental carbon (EC) sampling and analysis, in accordance with NIOSH Method 5040 [12]. In addition, "a multi-tiered exposure assessment strategy is recommended for CNT and CNF' [1].NIOSH also noted that this is important in order to determine the necessity and effectiveness of other measurement metrics in protecting workers' health. To this end, the efficacy of various other sampling techniques is currently being evaluated by NIOSH with a view to making additional recommendations in the future. To establish the thermal profile, a bulk sample of the nanomaterial should also be analyzed [12]. NIOSH anticipates that when the predominant workplace exposure to EC material is CNT or CNF, a reasonable estimate of a worker's respirable exposure can be obtained from measurement results using NIOSH Method 5040 at the NIOSH REL of $1 \mu \mathrm{g} / \mathrm{m}^{3} 8$-hr TWA [12]. Also, to ensure that exposures are maintained below the REL, NIOSH recommends that an exposure-monitoring program be established at the affected facility.

Key program elements include a plan designed to [1]:characterize exposures for at risk workers; identify other sources of potential exposures that may interfere with the interpretation of the results of exposures; identify specific tasks where exposures exceeded occupational limits; and assess the effectiveness of engineering controls, work practices, and PPE. The plan can be effectively implemented by developing a good exposure assessment strategy that puts into consideration the number of potentially exposed workers, individual worker-to-worker variability, and the day-to-day differences in airborne concentrations [1].A typical plan will include the development of process inventory and job hazard analysis to determine the number of potentially exposed workers; conducting a qualitative risk assessment to determine the highest potential for exposures; evaluating airborne concentrations, and development of activity data useful for identifying possible causes of high exposures. Also, there is need to evaluate exposure results and compare these with applicable standards or guidelines, and to implement appropriate control measures for worker protection.

Some important considerations for these control strategies include the uniqueness of each workplace (i.e., the number of workers, complexity of the task, including physical state and properties of the nanomaterial, process type, rate of operation, relevant exposure control methods, and available resources. It has also been noted that targeting similarly exposed groups of workers is an important first step for determining worker exposure. However, in order to reduce the potential for variability and avoid incomplete or upwardly biased estimates of exposure data, repeated and multi-day random airborne measurements of selected workers is recommended to account for between- and within-worker variation in exposure concentrations [1]. A detailed illustration of the necessary steps required for exposure assessment for CNTs and CNFs in situations where exposures exceeded the occupational exposure limits are adequately explained by NIOSH [1].

In addition to controlling exposures below the REL, it is prudent for employers to institute workplace assessment including medical surveillance and screening programs for workers exposed to CNT and CNF for the purpose of possibly detecting early signs of adverse pulmonary effects such as fibrosis. Also, should there be any inadequacy in controlling exposures below acceptable levels workplace assessment can provide a secondary level of prevention. NIOSH had previously concluded that based on available peer-reviewed research there was insufficient evidence to recommend specific medical tests for workers exposed to the broad category of engineered nanoparticles [17]. However, NIOSH noted that when relevant toxicological information becomes available in the future, specific medical screening recommendations would be made for workplace protection. In addition to controlling workplace exposures and providing medical surveillance, other risk management practices, including training and the use of personal protective equipment (e.g., respirators)are recommended [1], [17].

\section{B. Exposure Control Strategies}

As previously stated, there are currently no specific enforceable occupational exposure limits for airborne exposure to CNTs and CNFs established by regulatory agencies. In recognition of this fact and considering the need 
to develop adequate protective or control measures and promote safe advancement of nanotechnology, a number of recommendations are described in this article. Additionally, it is very important to have research data that effectively describe the potential health hazards and risks posed by exposure to CNTs and CNFs in industrial workplaces. Therefore it is important to be mindful of the potential health risks of exposure and to prevent potential medical and economic losses. Typically, when there are no less hazardous substitutes to minimize chemical exposures, three categories of control measures are often considered in industrial hygiene and they include engineering controls, administrative or work practice controls, and personal protective equipment. The decision to employ these controls should be based on available toxicity data, measured workplace concentrations and other applicable exposure information [1]. Table I provides a listing of some recommended guidelines that may be implemented to minimize exposures to CNTs and CNFs.

\section{Engineering Controls}

Engineering control is considered the first choice for workplace control of airborne chemical exposures. It is the most efficient and effective of all the three methods in minimizing occupational exposure since Ii focuses on eliminating the contaminants at the point of generation, thus getting rid of the nanoparticles before they can reach the worker's breathing zone.

- Local Exhaust Ventilation (LEV) system equipped with high efficiency particulate air (HEPA) filter ensures that the worker is isolated from the source of exposure to CNTs and CNFs. Collection of airborne particles occur sinside the hood during normal work procedures that may cause agitation or generation of these particles [1]. The conventional LEV system uses a well-designed hood or enclosure attached to process equipment that exhausts particle-laden air onto the collection equipment.

- Down Flow Booth is designed as a small room or enclosure with low velocity (typically $100 \mathrm{feet} /$ minute) that uses downward airflow to push or pull contaminants away from the worker's breathing zone. It is important that the booth's air volumes and control velocities be monitored and maintained periodically. Capture emissions from the booth may be affected by individual worker technique and interface with the work process.

- Closed Process Design (Process Isolation) ensures that the emission source is adequately confined and that all steps of the process or task are sealed with little or no chance of worker exposure. As long as the enclosure in the isolator is periodically cleaned, it minimizes external contamination and the need for respirators. However, the workersmust be trained in the correct use of the process and it has a major disadvantage due to the limitation in the size of material that can be placed inside the isolator.

\section{Administrative or Work Practice Controls}

Administrative control involves altering the work schedule to limit the amount of time a worker can be exposed to nanoparticles. It requires the implementation of good work practices and it may be necessary to increase the number of workers so as to minimize individual worker exposure.
Workers must be periodically trained and educated about the potential hazards associated with each process or operation to ensure ongoing improvements in knowledge base and work practices. Management commitment and support for workplace safety is an important requirement of this control measure so that affected workers can develop skills to perform their job safely.

TABLE I: EXPOSURE CONTROL STRATEGIES FOR CNTS AND CNFS

\begin{tabular}{|c|c|c|}
\hline Control & Characteristics & Comments \\
\hline $\begin{array}{l}\text { Engineer-ing } \\
\text { Control }\end{array}$ & 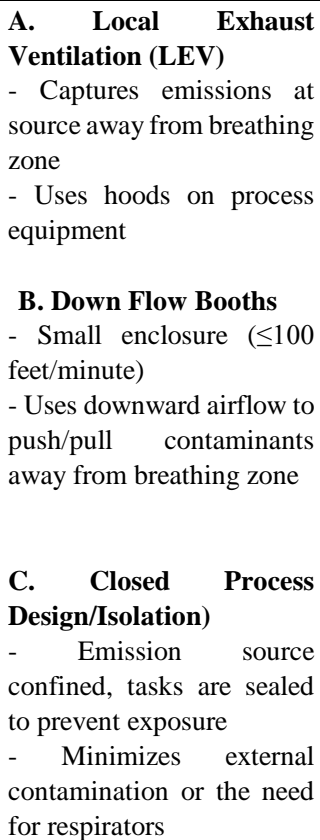 & $\begin{array}{l}\text { - Enclosure must } \\
\text { adequatelyisolate worker } \\
\text { from point of generation } \\
\text { - LEV with high efficiency } \\
\text { particulate air (HEPA) } \\
\text { filters } \\
\text { - Booth's air volumes and } \\
\text { control velocities must be } \\
\text { monitored and maintained } \\
\text { - Capture emissions } \\
\text { affected by worker } \\
\text { technique and work } \\
\text { process interface the } \\
\text { - Workers trained to } \\
\text { correctly use of booth } \\
\text { - Limitations on size of } \\
\text { material that can be placed } \\
\text { inside of a process isolator } \\
\text { - Need to periodically clean } \\
\text { the enclosure in the isolator }\end{array}$ \\
\hline \multirow[t]{2}{*}{$\begin{array}{l}\text { Work Practice } \\
\text { Control }\end{array}$} & $\begin{array}{l}\text { - Workers must be trained } \\
\text { on job hazards } \\
\text { - Improvements in } \\
\text { knowledge base and work } \\
\text { practices } \\
\text { - Workers develop skills to } \\
\text { perform job safely } \\
\text { - Management } \\
\text { commitment and support } \\
\text { for safety }\end{array}$ & $\begin{array}{l}\text { Guidelines for training } \\
\text { program } \\
\text { - Written procedures } \\
\text { - Top management support } \\
\text { and commitment } \\
\text { - Identify and communicate } \\
\text { hazards } \\
\text { - Assess exposures } \\
\text { - Document risk assessment } \\
\text { and management actions } \\
\text { - Identify and implement } \\
\text { controls } \\
\text { - Review effectiveness of } \\
\text { control practices } \\
\end{array}$ \\
\hline & & $\begin{array}{l}\text { Instruction for "Hands-on" } \\
\text { training program } \\
\text { - Potential health risks } \\
\text { - Safe handling }\end{array}$ \\
\hline $\begin{array}{l}\text { Personal } \\
\text { Protective } \\
\text { Equipment } \\
(\mathrm{PPE})^{1} \\
\end{array}$ & $\begin{array}{l}\text { - NIOSH-approved N95 or } \\
\text { elastomeric } \\
\text { half-face-piece respirators } \\
{[1]}\end{array}$ & $\begin{array}{l}\text { Apply all elements of } \\
\text { OSHA's } \quad \text { Respiratory } \\
\text { Protection Program (29 } \\
\text { CFR 1910.134) } \\
\end{array}$ \\
\hline
\end{tabular}

${ }^{1}$ Currently, there is no regulation or guideline for the selection of PPE to control exposures to CNTs and CNFs. OSHA considers PPE as the last line of defense against chemical hazards

${ }^{2}$ Elements of a respiratory protection program must be in accordance with the guidelines set forth in the Occupational Safety and Health (OSHA)'s Respiratory Protection Standard (29 CFR 1910.134). These include medical monitoring and evaluation, annual training and hazard communication, periodic workplace exposure monitoring, procedures for selection and fit-testing of respirators, and maintenance, inspection, cleaning, and storage procedures for respirators.

In addition to the above, there are other ways of minimizing occupational exposure to CNTs [1] and CNFs. Precautionary measures and prudent work practices include safe handling of nanomaterial, proper cleanup of any spills, efficient 
hand-washing techniques, avoiding food consumption in work areas, removal of laboratory coats prior to leaving the workplace, availability of facilities to shower and change clothing, and discarding heavily soiled coats are essential.

a. Personal Protective Equipment

Personal protective equipment (PPE) is the third and the least preferred method of control. This control method entrusts the responsibility of injury prevention on the employee and not the employer, the degree of efficacy of the devices may be questionable, and it often provides some form of inconveniences to the worker. PPE is considered the last line of defense against chemical hazards and in cases where engineering and administrative controls cannot be implemented, their use becomes paramount. There are currently no regulations or guidelines for the selection of PPE to control workplace exposure to CNT and CNF [1]. However, PPE can be used in combination with any of the other two types of controls described above. The use of NIOSH-approved N95 filtering face piece respirators or elastomeric half-face piece particulate respirators equipped with a 95 or 100 series $9 \mathrm{~N}, \mathrm{R}$ or P) filter have been shown to be adequate in protecting workers from inhalation of nanomaterial [1], [16]. For workplaces where the airborne concentrations of CNTs and CNFs exceed $1.0 \mathrm{mg} / \mathrm{m}^{3}$, a number of powered air purifying respirators with a hood/helmet (assigned protection factor or APF $=1000$ ) are recommended [1]. It must be noted that respiratory protection can be affected by a number of factors, including the user's ability to adhere to a complete program requirements as stipulated by OSHA in 29 CFR 1910.134, adhering to the use of NIOSH-certified respirators by the employer, and proper fit-testing of the individual worker [1], [16].

A previously published report by NIOSH [1], medical surveillance and screening programs are helpful in determining the efficacy of control measures as well as the need for more interventions. NIOSH [1] also recommends the reduction of airborne exposure below the REL and considers it the least airborne concentration that can be assessed with a reasonable degree of accuracy that would limit adverse respiratory effects that may occur with continuous exposures over a long period of time [1], [5].

\section{CONCLUSIONS}

CNTs and CNFs represent an important class of newly developed man-made elongated nanoparticles comprised of sheets of pure carbon. The biological mode of action is often attributed to their physical and chemical properties (nano-structure, fiber shape, and graphitic structure).A number of peer-reviewed scientific literature from experimental animal studies have documented potential hazards from airborne exposures to CNT and CNF and risk management practices and other recommended steps that should be implemented to control or minimize potential health risks. Due to their respiratory hazards, exposures to CNTs and CNFs should be controlled below NIOSH recommended exposure limit of $1 \mu \mathrm{g} / \mathrm{m}^{3}$ as 8 -hr TWA over a working lifetime of 45 years or as low as possible [1]. According to NIOSH, employers and their employees must take necessary steps to minimize exposure to CNT and CNF through well-understood, cost-effective, and feasible interventions. Other measures include occupational health surveillance and medical screening programs.

It is important that a multi-tiered exposure measurement strategy be developed to effectively determine exposure and limit workers' risks to CNT and CNF [1]. A number of other measures are recommended based on the application of sound industrial hygiene control techniques that are considered essential in designing effective local exhaust ventilation systems or in choosing appropriate respiratory protection [16]. It is also important that prudent exposure and hazard assessment procedures be followed in determining the need for and selection of appropriate and effective respirators [18]. To be effective, the program must include hazard communication and periodic training of workers on the sources and job tasks that may expose them to CNT and CNF as well as the correct use of process controls, work practices, and personal protective equipment to minimize exposure [18]. Finally, the precautionary principle should be applied whenever there is insufficient information on hazard analysis and workers' exposures to CNTs and CNFs.

Nanotechnology researchers worldwide have made considerable progress towards recognizing, identifying, assessing, and evaluating potential toxicity, health effects, worker exposure, and risk of nanomaterials during the last decade [1], [16]. However, there is urgent need for additional studies on human health impacts and to develop occupational exposure limits for specific nanoparticles and nanostructured materials such as CNTs and CNFs. To this end, NIOSH has initiated occupational exposure studies that would shed more light in adequately quantifying employee exposures with a view to developing guidance documents (i.e., recommended exposure limits) to eliminate exposures as well as recommend effective prevention and control techniques for processes and applications involving CNTs, CNFs, and other nanomaterials. Additionally, experimental and human studies are needed to assess the risks of developing lung fibrosis and cancer since it has been proposed that CNTs and CNFs have similar mechanisms of toxicity with asbestosis, a known cause of mesothelioma. These data would subsequently be applied to various exposure metrics (i.e., mass, tube, counts, surface area chemistry, etc.) in evaluating toxicological responses of exposures to different types of CNTs and CNFs.

\section{REFERENCES}

[1] NIOSH. (2013). Occupational exposure to carbon nanotubes and nanofibers. Current Intelligence Bulletin 65. National Institute for Occupational Safety and Health, Centers for Disease Control and $\begin{array}{lll}\text { Prevention. } & \text { [Online]. Available: }\end{array}$ http://www.cdc.gov/niosh/docs/2013-145/pdfs/2013-145.pdf

[2] N. Invernizzi, "Nanotechnology between the lab and the shop floor: What are the effects on labor?' Journal of Nanopart Res, vol. 13, no. 6, pp.2249-2268, 2011.

[3] C. Lam, J. T. James, R. McCluskey, S. Arepalli, and R. L. Hunter, “A review of carbon nanotube toxicity and assessment of potential occupational and environmental health risks," Critical Reviews in Toxicology, vol. 36, no. 3, pp. 189-217, 2006.

[4] K. Donaldson, R. Aitken, L. Tran, V. Stone, R. Duffin, G. Forrest, and A. Alexander, "Carbon nanotubes: A review of their properties in relation to pulmonary toxicology and workplace safety," Toxicological Sciences, vol. 92, no. 1, pp. 5-22, 2006.

[5] M. M. Dahm, D. E. Evans, M. K. Schbauer-Berigan, M. E. Birch, and J. A. Dedens, Occupational exposure assessment in carbon nanotube 
and nanofiber primary and secondary manufacturers: Mobile direct-reading sampling, "Annals of Occupational Hygiene," vol. 57, no. 3, pp. 328-344, 2013.

[6] M. Eileen Birch, B. Ku, D. E. Evans and T. A. Ruda-Eberenz, "Exposure and emissions monitoring during carbon nanofiber production Part I: Elemental carbon and iron-soot aerosols," Annals of Occupational Hygiene, vol. 55, no. 9, pp. 1016-1036, 2011.

[7] P. Schulte, C. Geraci, R. Zumwalde, M. Hoover, and E. Kuempel, "Occupational risk management of engineered nanoparticles," Journal of Occupational and Environmental Hygiene, vol. 4, no. 4, pp. 239-249, 2008

[8] Wikipedia. Precautionary principle. [Online]. Available: http://en.wikipedia.org/wiki/Precautionary_principle

[9] D. Kriebel et al., "The precautionary principle in environmental science," Environmental Health Perspectives, vol. 109, no. 9, pp. 871-876, 2001

[10] E. K. Rushton et al., "Concept of assessing nanoparticle hazards considering nanoparticle dosemetric and chemical/biological response metrics," Journal of Toxicology and Environmental Health, Part A. Current Issues, vol. 73 no. 5-6, pp. 445-461, 2010.

[11] K. Savolainen, H. Alenius, H. Norppa, L. Pylkkanen, T. Tuomi, and G. Kasper, "Risk assessment of engineered nanomaterials and nanotechnologies - A review," Toxicology, vol. 269, no. 2-3, pp. 92-104, 2010.

[12] M. E. Birch, "NIOSH Method 5040 update," U.S. Department of Health and Human Services, Centers for Disease Control and Prevention, National Institute for Occupational Safety and Health, DHHS (NIOSH) Publication No. 2003-154, 2004.

[13] P. A. Schulte, V. Murashov, R. Zumwalde, E. D. Kuempel, and C. L. Geraci, "Occupational exposure limits for nanomaterials," Journal of Nanoparticles, vol. 12, pp. 1971-1987, 2010.

[14] D. E. Evans et al., "Dustiness of fine and nanoscale powders," Annals of Occupational Hygiene, vol. 57, no. 2, pp. 261-277, 2013

[15] A. D. Maynard, P. A. Baron, M. Foley, A. A. Shvedova, E. R. Kisin, and V. Castranova, "Exposure to carbon nanotube material: Aerosol release during the handling of unrefined single- walled carbon nanotube material," Journal of Toxicology and Environmental Health, Part A: Current Issues, vol. 67, no. 1, pp. 87-107, 2004.

[16] V. Castranova, P. A. Schulte, and R. D. Zumwade, "Occupational nanosafety considerations for carbon nanotubes and carbon nanofibers", Accounts of Chemical Research, vol. 46, no. 3, pp. 642-649, 2013.

[17] National Institute for Occupational Safety and Health, "NIOSH current intelligence bulletin 60: Interim guidance for medical screening and hazard surveillance for workers potentially exposed to engineered nanoparticles," U.S. Department of Health and Human Services, Centers for Disease Control and Prevention, DHHS, NIOSH Publication No. 2009-116, 2009.

[18] R. E. Shaffer and S. Rengasamy, "Respiratory protection against airborne nanoparticles: A review," Journal of Nanopart Res, vol. 11, no. 7, pp. 1661-1672, 2009.

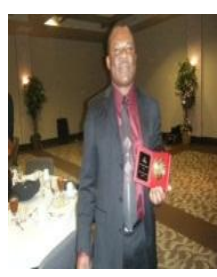

Emmanuel A. Iyiegbuniwe is currently an associate professor and director of Environmental Health Science/National Institute for Occupational Safety and Health (NIOSH) Training Project Grant at Western Kentucky University (WKU). Professor Iyiegbuniwe received his $\mathrm{MS}$ and $\mathrm{PhD}$ degrees in environmental \& occupational health sciences from the University of Illinois at Chicago, MBA from WKU, and BS and MS degrees in microbiology from Universities of Lagos and Ife in Nigeria. His teaching philosophy is a very simple one that stems from a student-centered doctrine and is clearly demonstrated in my belief that "all students want to learn; success breeds success." Professor Iyiegbuniwe has taught many graduate and undergraduate courses, including epidemiology, environmental health, air quality management, industrial hygiene, toxicology, air pollution control, risk assessment, food safety, and public health management of disasters. He routinely supervise students' thesis, capstone projects, independent studies, and conference presentations, and routinely serve as advisor and mentor to our students and their organizations. He has expertise in developing and delivering comprehensive environmental and occupational health programs, exposure assessments, and in fostering interdisciplinary international service learning collaborations and research. Professor Iyiegbuniwe has over twenty years of academic, administrative, and consulting experiences and believes that a true scholar must integrate teaching, research, and service with life-long experiences. He currently serves as a Steering Committee member for the NIOSH Pilot Research Project at the University of Cincinnati, a Judge at the Annual Biomedical Research Conference for Minority Students (ABRCMS), and on several dissertation committees for doctoral degree students. He is a Thomas Jefferson scholar, a fellow of AIHA's Future Leaders Institute, CDC's EPHLI, and AASCU/Nippon Foundation's Scholarship.

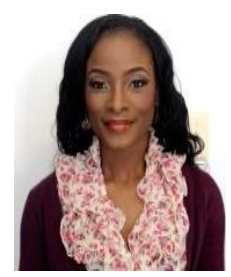

Usonwanne Nwosu earned her medical degree from the University of Nigeria, Enugu College of Medicine. Upon completion of her Medical School Education, Dr. Nwosu worked as a house officer at two Nigerian hospitals: The Univerisity of Calabar Teaching Hospital and Sabon-Tasha General Hospital in Kaduna. Subsequently, Dr. Nwosu proceeded to Western Kentucky University (WKU) for her graduate studies in public health and obtained a master of public health (MPH) degree in environmental health science in 2014. While in the MPH program she worked as a graduate assistant at WKU's Alive Center, where she was involved with community development and community based research projects. She is currently an internal medicine resident physician at St. Vincent's Medical Center in Bridgeport, Connecticut, USA.

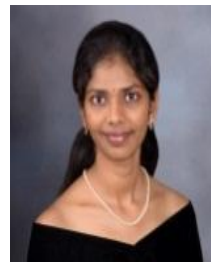

Sireesha Kodali earned her dental degree from Vishnu Dental College in India. Upon completion of her dental school education. Sireesha worked as an associate dental surgeon at Krishna Sai Dental Clinic, India. Dr. Kodali then proceeded to Western Kentucky University (WKU) for her graduate studies in public health and obtained a master of health care administration (MHA) degree in 2013. While in the MHA program, she worked as a graduate assistant in Public Health Department, where she was involved with public health promotion and statistically involved research projects. She is currently enrolled in a dual doctor of dental medicine (DMD) and masters in oral biology program at University of Louisville School of Dentistry, Louisville, Kentucky (expected graduation in 2016). 